Federal Reserve Bank of Minneapolis Research Department

\title{
Costly Banknote Issuance and Interest Rates Under the U.S. National Banking System
}

\author{
Antoine Martin, Cyril Monnet, \\ and Warren E. Weber* \\ Working Paper 601
}

May 2000

\begin{abstract}
The behavior of interest rates under the U.S. National Banking System is puzzling because of the apparent presence of persistent and large unexploited arbitrage opportunities for note issuing banks. Previous attempts to explain interest rate behavior have relied on the cost or the inelasticity of note issue. These attempts are not entirely satisfactory. Here we propose a new rationale to solve the puzzle. Inelastic note issuance arises endogenously because the marginal cost of issuing notes is an increasing function of circulation. We build a spatial separation model where some fraction of agents must move each period. Banknotes can be carried between locations; deposits cannot. Taking the model to the data on national banks, we find it matches the movements in long-term interest rates well. It also predicts movements in deposit rates during panics. However, the model displays more inelasticity of notes issuance than is in the data.
\end{abstract}

Keywords: Interest rates, National Banking System, banknotes, spatial separation

$J E L$ classification numbers: E42, N21

*Martin, University of Minnesota and Federal Reserve Bank of Minneapolis; Monnet, University of Minnesota and Federal Reserve Bank of Minneapolis; Weber, Federal Reserve Bank of Minneapolis and University of Minnesota. We are indebted to Gaetano Antinolfi, Randy Wright, and participants at seminars at Iowa State University and Rutgers University and at the Money and Payments Systems Conference at Purdue University for helpful comments on an earlier version of the paper. Address correspondence to Weber at wew@res.mpls.frb.fed.us. The views expressed herein are those of the authors and not necessarily those of the Federal Reserve Bank of Minneapolis or the Federal Reserve System. 


\section{Introduction}

In 1863, the United States established the so-called National Banking System. Under this system private commercial banks (national banks) were permitted to issue liabilities (bank notes) that had to be fully collateralized by government bonds deposited with the U.S. Treasury and that had to be redeemed on demand at par in "lawful money" - specie or legal tender notes ("greenbacks"). A bank was subject to a tax on its notes, but the tax was applied only to the quantity of notes actually in circulation. ${ }^{1}$ The notes of national banks carried an explicit government guarantee against noteholder loss should the issuing bank fail. It is generally accepted that national bank notes were perfect substitutes for specie and legal tender notes in circulation.

Many authors have noted that the behavior of interest rates under the National Banking System was puzzling, because arbitrage opportunities apparently were left unexploited. ${ }^{2}$ The collateral constraint on the issue of bank notes was never binding. In fact, national banks held more government bonds than were required as collateral for the notes they issued. The perfect substitutability of national bank notes and lawful money would seem to argue that national banks could keep their notes in circulation indefinitely. They could use these notes to purchase government bonds or other assets. Profit-maximization suggests that banks should have bid the price of assets up (the yield on assets down) to the point where the yield was equal to the banks' cost of issuing notes. Since these notes were considered perfect substitutes for lawful money, they carried a nominal interest rate of zero. The tax rate on note

\footnotetext{
${ }^{1}$ The tax was assessed on January 10 and July 10 on the average amount of notes that a bank had in circulation in the six months previous to the assessment date.

${ }^{2}$ See Bell 1912; Cagan 1963, 1965; Cagan and Schwartz 1991; Champ 1990; Champ, Freeman, and Weber 1999; Champ, Smith, and Williamson 1996; Champ, Wallace, and Weber 1992, 1994; Friedman and Schwartz 1963; Goodhart 1965; James 1976; Kuehlwein 1992.
} 
issues was one percent, one-half percent after 1900. The other costs associated with note issue also should have been relatively constant. Such arbitrage arguments imply that the yield on government bonds, or other safe assets should have been constant at approximately one percent up to 1900, then fallen by one-half percent and remained constant at that new level thereafter.

Asset yields during this period, however, did not follow this pattern. In Figure 1 we plot the yields on three government bonds issues that made up the vast majority of the collateral for national bank notes at monthly intervals for the period 1882 to $1913 .^{3}$ The figure shows that asset yields were consistently higher than the level implied by the elimination of arbitrage opportunities. Further, yields were not constant. Instead, yields declined from 1882 through the middle of 1889 . From the middle of 1889 through the fall of 1896 bond yields increased, exceeding their levels in 1882. Yields then declined sharply until 1901 or 1902, depending upon which bond yield is being considered. From 1902 through 1913, bond yields generally showed a slight upward trend. Thus, the figure shows that there apparently were persistent and large arbitrage opportunities during this period. The persistence and magnitude of these apparent arbitrage opportunities have led Cagan and Schwartz 1991 to dub this phenomena the "National Bank note puzzle". ${ }^{4}$

\footnotetext{
${ }^{3}$ During this period, there were only a few issues of government bonds in existence at any point in time. These issues were all long-term and were identified by their coupon rate and the date at which they first became callable. Thus, for example, the $4 \mathrm{~s}$ of 1907 were four percent coupon bonds that were first callable in 1907. The yields shown in Figure 1 are calculations based upon end-of -month bond price data collected from the Commercial and Financial Chronicle by Bruce Champ and James Thomson and kindly provided to us. All calculations were done using the "yield" worksheet function in Excel, assuming that coupons are on the first day of the month that they were scheduled to be paid and that bonds were expected to mature on the first date at which they could be called.

${ }^{4}$ Sometimes the puzzle is stated as, If bank notes issuance was profitable, why were fewer bank notes issued than was permitted by the constraint that notes had to be collateralized by deposit of government bonds? For reasons that will become obvious later, we have chosen the alternative of framing the puzzle in terms of the persistence of an arbitrage opporunity.
} 
Several solutions to the puzzling behavior of interest rates have been proposed. Some of these and the reasons we think they are inadequate are discussed below. Our purpose in this paper is to present another potential solution to the puzzle. Our solution is to modify the assumption that the costs of bank note issuance were roughly constant across the quantity of notes issued. Instead, we assume that there is some quantity of notes, what we will term "cheap notes", that have a constant and low marginal cost because banks expect that these notes will stay in circulation for long periods of time. However, they also expect that notes issued beyond that quantity, particularly those issued in times of high demand, carry a higher marginal cost. We will call these "expensive notes". One possible reason these notes have a higher marginal cost is that such notes could be expected to be returned to the bank (presented for redemption) very quickly. ${ }^{5}$ Another possible reason is that note issuance beyond some point could leave the bank vulnerable to portfolio shocks that would threaten the bank's solvency. The presence of this friction in the marginal cost of note issuance introduces a form of endogenous inelasticity to bank note issuance. This inelasticity permits interest rates to be higher than the tax rate and to fluctuate with changes in the demand for notes.

We will judge the success of our model by the ability of a reasonably parameterized version to explain certain secular and cyclical facts during this period. In particular, we want to explain

\footnotetext{
${ }^{5}$ This idea also appears in Champ, Wallace, and Weber 1996, but it is not explicitly modeled there.
} 
- the level of and movements in long term interest rates

- changes in the quantity of bank notes issued, and

- the magnitudes of the discounts on certified checks, the quantity of bank notes issued, and the level of call loan rates during financial panics.

The paper proceeds as follows. In section 2, we review the previous literature. In section 3, we present the model. In section 4, we discuss some data issues and describe our parameterization of the model. In section 5, we discuss how well the parameterized model explains the facts. In section 6 , we conclude.

\section{Previous explanations}

In this section, we present and evaluate some previous suggested solutions to the puzzling behavior of interest rates under the National Banking System. One of these is given in Champ, Freeman, and Weber 1999. They argue that the expected cost that banks have to bear when their notes are presented for redemption should be added to the tax in terms of evaluating the magnitude of the arbitrage opportunity. However, they find that the magnitude of these costs is not sufficiently large to make the arbitrage opportunity go away. Further, they find that the secular movements in these costs do not correspond to the secular movements in asset yields.

Another explanation of the puzzle is given in Champ, Smith, and Williamson 1996. They build an OLG spatial separation model of bank note issuance. When bank note issuance is perfectly elastic, the interest rate on loans, which can be considered to be the yield on government bonds, is equal to the cost of note issue. (The same result is obtained in Champ,

Wallace, and Weber 1996.) However, when note issuance is perfectly inelastic, the interest 
rate on loans is above the cost of note issuance and changes in the demand for bank notes give rise to interest rate fluctuations. Champ, Smith, and Williamson 1996 argues that the perfectly inelastic note issuance case more nearly characterizes the National Banking System. They argue there were institutional constraints, described only as the "mechanics of note issue," that prevented national banks from changing the amounts of notes that they had in circulation, at least in the short run. We agree that in the aggregate, the supply of national bank notes appears to have been inelastic. To get an idea of high frequency changes in national bank circulation, for the period 1881 to 1910 we plot the percentage changes in total circulation between call report dates for each of the five call reports that national banks were required to file each year. (Although these call reports are not at evenly spaced time intervals, we have treated them as such for purposes of plotting the data.) This is done in Figure $2 .{ }^{6}$ This figure makes two points. First, there was not much high frequency fluctuation in the quantity of national bank notes in circulation. The average absolute percentage change was only 2.5 percent. Further, there are only 19 times, out of the 150 observations in Figure 2, in which national bank circulation changed by more than five percent in either direction between call reports and only 4 times in which it increased more than ten percent in either direction.

However, we disagree that the cause of the inelasticity was exogenous, rather than being the result of optimizing behavior on the part of banks. There are three reasons. First, banks held government bonds beyond that required to collateralize their circulation. Since

\footnotetext{
${ }^{6}$ Weber 2000 has compiled the disaggregated call reports by state and reserve city for each call report date. All national bank data used in this paper are aggregates of these data, rather than the aggregates reported by the Comptroller of the Currency. The reason is in many cases the totals given in the Comptroller's aggregates do not agree with the totals from this disaggregated reports.
} 
the tax was only on circulation, it would have been costless for banks to have idle notes in their vaults to meet increased demands. Second, much of the increased demand for notes was predictable due to its seasonality so the mechanics of note issue would not have prevented national banks from having additional notes on hand in a timely manner. Third, there were large secular (low frequency) movements in national bank note circulation. We have plotted the level of national bank note circulation at each call report date in Figure $3 .^{7}$ The figure shows that bank note circulation declined by slightly over 60 percent between the end of 1881 and the end of 1890. After that, circulation increased slowly until the end of 1899 after which it increased at a far more rapid pace. By 1913, national bank note circulation was more than six times greater than it was in 1890 .

\section{The model}

We consider an overlapping generations economy with two-period lived households and two locations. Time is discrete, infinite, and indexed by $t=0,1, \ldots$ There is a single, non-storable consumption good, denoted $x(t)$, in each location in each period. Consumption goods are not transferable across locations. Locations are physically distinct, so that it is not possible for agents or banks to communicate across locations.

A continuum of identical households of measure one is born in each location in each period. Half of the measure of households in each location, "lenders", receive an endowment of the consumption good $z_{t}(t)>0$ only in the first period of life. The other households, "borrowers", receive an endowment of the consumption good $y_{t}^{*}(t+1)>0$ only in the second

\footnotetext{
${ }^{7}$ We also examined net circulation, measured as total circulation less holdings of bills of other banks, of national bank notes. The movements in the two series are virtually identical, so we did not plot net circulation in the figure or discuss it in the text.
} 
period of life. We assume that although the money in this economy is commodity money, it does not yield any direct utility to the holders.

There are also a large number of banks in each of the two locations. These banks are infinitely lived (although one could think of banks as also two-period lived with a new cohort of banks coming into existence in each period). These banks can take deposits, issue bank notes, and make loans.

Lenders do not necessarily remain in the same location for their entire lives. Some measure of lenders of each cohort spend the first period of their lives at one location and the second period of their lives at the other location. Although whether or not a particular young lender has to move and the measure of young lenders that have to move are public information, this information is not revealed until the end of the agent's first period of life. The probability that a young lender of cohort $t$ will move is $\pi(t, j)$, where $j=g, b$ is the state of the economy at time $t$. There are two states, good $(g)$ and bad $(b)$, such that $\pi(t, g)<\pi(t, b)$. That is, fewer young lenders have to move in the good state than have to move in the bad state. Thus, the bad state can be thought of as a bank run. The probability that the good state occurs at time $t$ is $\alpha(t, g)$.

It is the combination of impossibility of communication across locations with the fact that some households must move that gives rise to the need for banknotes. The impossibility of communication means that a household (or bank) in one location cannot verify that the check written on a bank in another location is good (not counterfeit) or not. Banknotes are not counterfeitable, by assumption. Thus, a young household that has to move will want bank notes or specie, since deposits will be useless in its new location. The assumption that bank notes can be used for transactions at far locations, whereas deposits are restricted to 
near locations, is an attempt to capture the transactions facts of the national banking period. Specifically, Sprague 1910 says, "A far more serious cause of disturbance from the suspension of payments is the dislocation of the domestic exchanges. In making payments at a distance local substitutes for money will not serve. When banks in one locality refuse to remit to banks elsewhere upon drafts and checks sent to them for payment business must soon come to a standstill." (p. 75)

A national bank had to pay a tax on the amount of its notes in circulation. In addition, it was charged for costs of sorting and shipping any of its notes that were presented for redemption through the redemption facility at the U.S. Treasury. Further, national banks incurred fixed costs, the wages of tellers and the cost of having a vault, associated with note issue. With these considerations in mind, we model the costs of note issuance as follows. Banks can issue two kinds of notes. There are "cheap" notes, denoted $B(t, j)$, which it can issue in state $j$ in time $t$. These notes carry a redemption cost of $c_{B} \geq 0$ per note, payable in period $t+1$. There are also "expensive" notes, denoted $N(t, j)$, which it can issue in state $j$ in time $t$. These notes carry a redemption cost of $c_{N}>c_{B}$ per note, also payable in period $t+1$. The reason that banks would ever choose to issue expensive notes is that there is a maximum amount of cheap notes, $\beta(t)$, that a bank can issue in any period. What we are trying to capture with the maximum on cheap note issuance is the idea that banks expect that there is some quantity of notes, $\beta(t)$, that will stay in circulation for a relatively long period of time. However, they also expects that notes issued beyond that quantity, particularly those issued in terms of high demand, will be returned to the bank (presented for redemption) very quickly. It is the presence of the upper bound on cheap note issue that drives the results of the model. 
The timing of transactions, the revelation of the state of the economy, and the moving of households is shown in Figure 4. At the beginning of a period of life, young lenders receive their endowments of the consumption good. They then decide how much of this endowment to deposit in one of the banks in the economy. After making the deposit, each young lender consumes. After this, young borrowers arrive at banks and take out loans at the non-state contingent gross nominal interest rate $R(t) \in \Re_{+}$. They then consume the consumption goods that they have borrowed.

Next old borrowers receive their endowments of the consumption good. They sell part of this endowment to old lenders for deposits, banknotes, and specie. They then consume the rest of their endowment, and they take the deposits, banknotes, and specie to banks to pay off the loans that they took out in the previous period. Old lenders consume the goods that they bought with their deposit, banknotes, and specie.

After banks receive payment for the loans they made last period, they adjust their holdings of specie to the desired level given the amount of deposits they have taken from and the loans they have made to the current period young. Thus, we are implicitly assuming that there is a market where banks can trade specie for goods or goods for specie at $p(t)>0$, the inverse of the price level in period $t$. If we think of our model as strictly of the banking sector, then this market is the rest of the economy. If we think of our model as the domestic economy, then this other market is the rest of the world, and banks' adjustment of specie holdings corresponds to international specie flows. Under this latter interpretation, we admit that there is some inconsistency, because we are, in effect, assuming that the economy is a small country with respect to goods, but a large or at least isolated economy in terms of capital. However, we chose as we did, because we wanted banks' decisions regarding reserves 
to be part of the determination of interest rates. After adjusting their specie holdings, banks in one location send the notes they have received as loan payments to the other location for redemption, receive back the notes they issued in the previous period, and pay the redemption costs on these notes.

Finally, the moving shock is revealed. Young lenders who stay in the same location do nothing. Movers go to their bank and redeem their deposits for specie (lawful money) or banknotes and then go to their new location.

\section{A. Household behavior}

All households have preferences

$$
u\left[x_{t}(t), x_{t}(t+1, j)\right]=\ln x_{t}(t)+\delta \ln x_{t}(t+1, j),
$$

where $x_{k}(t, j) \in \Re_{+}$denotes the consumption of a household of cohort $k$ in period $t$ in state $j$ and $\delta \in(0,1)$ is the rate of time preference. Households are assumed to maximize expected lifetime utility subject to their budget constraints. For borrowers the problem is simple:

$$
\max _{x_{t}(t), x_{t}(t+1)}\left[\ln x_{t}(t)+\delta \ln x_{t}(t+1)\right]
$$

s.t.

$$
x_{t}(t)+x_{t}(t+1) / r(t)=y_{t}^{*}(t+1) / r(t)
$$

where $r(t)=R(t) p(t+1) / p(t)$ is the gross real rate of interest between periods $t$ and $t+1$. 
Solving, borrowers' nominal demand for loans in period $t$ is

$$
p(t) \ell(t)=p(t) x_{t}(t)=Y(t+1) / R(t)
$$

where $Y(t+1)=(1+\delta)^{-1} y^{*}(t+1) / p(t+1)$.

The lenders' problem is more complicated. As we discuss below, banks offer statecontingent payment schedules for demand deposits. Specifically, let $R^{m}(t, j) \in \Re_{+}$be the gross nominal rate of return paid to depositors (lenders) who withdraw early (movers) in time period $t$ if state $j$ occurs, $R^{n}(t, j) \in \Re_{+}$be the gross nominal rate of return paid to depositors who do not withdraw early (nonmovers) in time period $t$ if state $j$ occurs, and $D(t)$ be the nominal deposits of lenders in period $t$. Then the consumption of movers and nonmovers in the second period of their lives will be $x_{t}(t+1, j)=p(t+1) R^{m}(t, j) D(t)$ and $x_{t}(t+1, j)=p(t+1) R^{n}(t, j) D(t)$, respectively. Thus, the lender's problem is

$$
\max _{x_{t}(t), D(t)}\left[\ln x_{t}(t)+\delta \sum_{j=g, b} \alpha(t, j)\left\{\pi(t, j) \ln \left[R^{m}(t, j) D(t)\right]+[1-\pi(t, j)] \ln \left[R^{n}(t, j) D(t)\right]\right\}\right]
$$

s.t.

$$
x_{t}(t)+p(t) D(t)=z(t)
$$

The solution for lenders' nominal deposits is

$$
D(t)=\delta(1+\delta)^{-1} z(t) / p(t) .
$$




\section{B. Bank behavior}

Banks take deposits, make loans, and pay out specie and banknotes. We assume that banks take as given the quantity of deposits, the interest rate at which they can make loans, the cost of bank note issue, and the constraint on the amount of cheap bank notes they can issue. However, we allow them to decide how many loans to make, how much specie to hold as reserves, and how many of each type of banknotes to issue. (We will make assumptions so that banks will never want to hold excess reserves, but will always want to issue notes.) Further, we permit banks to choose schedules of interest payments on deposits that depend upon the state of the economy and whether or not an individual is a mover or a nonmover.

Banks face three constraints on their behavior. First, banks must be able to meet the withdrawal demands of movers either out of their specie holdings or by issuing bank notes

$$
\pi(t, j) R^{m}(t, j) D(t)=S(t)+B(t, j)+N(t, j) \quad \forall t, j .
$$

The lefthand side of (1) is a bank's obligations in period $t$, the payments it promises to movers. The righthand side is a bank's resources to meet these obligations - its nominal specie holdings, denoted $S(t)$, and its issuance of both kinds of banks notes.

Second, in period $t+1$, banks must be able to meet the withdrawal demands of nonmovers and pay the costs of note issue out of their earnings from the loans they made in period $t$

$$
[1-\pi(t, j)] R^{n}(t, j) D(t)+c_{B} B(t, j)+c_{N} N(t, j)=R(t) L(t) \quad \forall t, j .
$$

Third, banks face the overall resource constraint that their loans plus reserves must 
equal their deposits

$$
L(t)+S(t)=D(t) \quad \forall t
$$

The equilibrium concept that we use is Nash equilibrium. Given that there are a large number of banks, this choice has two immediate implications. The first is that in equilibrium banks will earn zero profits, because if banks are earning profits, then there is an incentive for an individual bank to deviate and offer higher interest rates on deposits and thus attract all depositors. The second is that the deposit contracts offered by banks in equilibrium will maximize the utility of households, because if they do not, once again there are incentives for an individual bank to deviate.

Thus the banks' optimization problem is

$$
\max \sum_{t=0}^{\infty} \delta^{t} \sum_{j=g, b} \alpha(t, j)\left\{\pi(t, j) \ln \left[R^{m}(t, j) D(t)\right]+[1-\pi(t, j)] \ln \left[R^{n}(t, j) D(t)\right]\right\}
$$

subject to (1), (2), (3)

$$
\begin{gathered}
S(t) \leq D(t) \\
B(t, j) \leq \beta(t)
\end{gathered}
$$

$S(t) \geq 0$, and $B(t, j) \geq 0$. The maximization is over $\left\{R^{m}(t, j), R^{n}(t, j), L(t), S(t), B(t, j)\right.$, $N(t, j)\}$.

Substitute for $L(t)$ using (3) and let $\lambda(t, j), \theta(t, j), \mu(t), \nu(t, j)$ be the Lagrange multipliers for (1), (2), (4), and (5), respectively. The first order conditions for the banks' 
optimization problem are

$$
\begin{array}{cc}
\delta^{t} \frac{\alpha(t, j)}{R^{m}(t, j)}-\lambda(t, j) D(t)=0, & \forall t, j \\
\delta^{t} \frac{\alpha(t, j)}{R^{n}(t, j)}-\theta(t, j) D(t)=0, & \forall t, j \\
\lambda(t, j)-c_{B} \theta(t, j)-\nu(t, j) \leq 0, & \forall t, j \quad \text { with equality if } B(t, j)>0 \\
\lambda(t, j)-c_{N} \theta(t, j) \leq 0, & \forall t, j \quad \text { with equality if } N(t, j)>0 \\
\lambda(t, g)+\lambda(t, b)-R(t)[\theta(t, g)+\theta(t, b)]-\mu(t) \leq 0, & \forall t \quad \text { with equality if } S(t)>0 \\
\mu(t) \geq 0, \quad & \text { with equality if } S(t)<D(t) \\
\nu(j) \geq 0, \quad & \quad \text { with equality if } B(t, j)<\beta(t)
\end{array}
$$

and the constraints.

\section{Market clearing}

The market that has to clear in this model is that for loans. The quantity of loans sought by borrowers has to be equal to quantity of loans that banks are willing to make. That is

$$
Y(t+1) / R(t)=D(t)-S(t) .
$$

\section{Equilibrium}

For defining equilibrium in this economy, we face a choice of whether to take prices or the quantity of specie as exogenous. We choose prices for the reasons given above. 
Definition 1. Positive reserves and note issuance equilibrium.

Given $\left\{z(t), y^{*}(t), p(t), \beta(t), \alpha(t, j), \pi(t, j)\right\}, \delta, c_{B}$, and $c_{N}$, a set $\left\{R^{m}(t, j), R^{n}(t, j), R(t)\right.$, $S(t)>0, B(t, j)>0, N(t, j) \geq 0\}$ is a Nash equilibrium with positive reserves and note issuance if it satisfies household and bank maximization and loan market clearing.

The following lemma will be useful for the discussion which follows:

Lemma 1. Any positive reserves and note issuance equilibrium will have the properties:

1. $[\beta(t)-B(t, j)] N(t, j)=0$,

2. $c_{B} \leq R(t) \leq c_{N}$,

3. $c_{B} \leq \frac{R^{n}(t, j)}{R^{m}(t, j)}$ with equality if $B(t, j)<\beta(t)$,

4. $\frac{R^{n}(t, j)}{R^{m}(t, j)} \leq c_{N}$ with equality if $N(t, j)>0$,

5. $R^{m}(t, b) \leq R^{m}(t, g) \leq c_{N}$, and

6. $c_{B} \leq R^{n}(t, g) \leq R^{n}(t, b)$.

Proof: Properties (1) through (4) follow directly from the banks' first order conditions. Properties (5) and (6) follow immediately from Properties (2) through (4).

Property (1) states that a bank will not issue expensive notes in a state unless it has issued all the cheap notes it can in that state. Property (2) states that the nominal interest rate on loans has to at least cover the cost of issuing cheap notes, but has to be less than or equal to the cost of issuing expensive notes. This has to hold because at the margin loans are funded by the issue of bank notes. Properties (3) and (4) states that the ratio of the interest rates paid to nonmover and movers must always be at least as large as $c_{B}$, but can never exceed $c_{N}$. If a household were to switch from being a mover to being a nonmover, then the 
bank would save the cost of issuing notes to this household. Competition means that these costs must be passed on to the household. Property (5) states that the interest rate paid to movers in the good state will always be at least as great as that paid to movers in the bad state, but that this interest rate will never exceed the cost of issuing the expensive notes. Property (6) states that the interest rate paid to nonmovers in the bad state will always be at least as great at the interest rate paid to movers in the bad state, and this interest rate will always be greater than the cost of issuing cheap notes.

\section{Assumption P:}

$$
c_{N}-\pi(t, g) c_{B}<\frac{Y(t+1)}{D(t)}<c_{B} \quad \forall t
$$

This assumption is sufficient to guarantee that banks will always want to hold positive amounts of reserves and to issue notes in both states.

Proposition 1. Under assumption $P$, a positive reserves and note issuance equilibrium exists.

Proof: The proof is given in the Appendix.

In writing the conditions for equilibrium, we noticed that interest rates could be written as functions of $Y(t+1) / D(t), \beta(t) / D(t)$, and the cost and probability parameters. A representative illustration of interest rate behavior in this model as a function of $Y(t+1) / D(t)$, holding the values of the parameters and other exogenous variables fixed, is shown in Figure 5. For small values of $Y(t+1) / D(t)$, we are in the case when banks do not hit the constraint on note issuance in either state. Here, as expected from the Lemma, $R(t)=R^{n}(t, g)=R^{n}(t, b)=c_{B}$ and $R^{m}(t, g)=R^{m}(t, b)=1$. 
As $Y(t+1) / D(t)$ increases, banks end up holding fewer specie reserves, either because they have fewer deposits or they are making more loans, if the interest rate is unchanged. At some point, they will not be able to pay off movers dollar for dollar when the bad state occurs because they hit the constraint on issuing cheap banknotes. This has the effect of raising the marginal cost of funding loans above $c_{B}$, so that the interest rate on loans has to rise above $c_{B}$. However, since the interest rate on loans has not yet risen high enough for it to be profitable for banks to issue expensive notes in the bad state, $R^{m}(t, b)$ must be less than unity. Further, since the return on loans has risen relative to the cost of note issue in the bad state, the difference must go to non-movers, meaning that $R^{n}(t, b)>c_{B}$. In addition, since $R(t)>c_{B}$, the profits that banks earn on loans above the cost of note issue in the good state must be split between movers and nonmovers, so that $R^{n}(t, g)>c_{B}$ and $R^{m}(t, g)>1$.

As $Y(t+1) / D(t)$ continues to increase, eventually $R(t)$ increases to the point that it now pays banks to issue expensive notes in the bad state. At this point, the slopes of the interest rate curves change, and for $R(t), R^{m}(t, g), R^{n}(t, g)$, and $R^{n}(t, b)$ the slopes become flatter. The reason is that now the marginal cost of funding loans is approximately a weighted average of $c_{B}$ and $c_{N}$ with constant weights.

Eventually, however, banks reach the point where they are holding so few specie reserves that they cannot pay off movers in the good state with cheap banknotes. After this point, all interest rates begin increasing until eventually interest rates are high enough so that it pays banks to also issue expensive notes in both states and we are in the case covered by the Lemma. Note that in this case the interest rate paid to nonmovers is higher than the interest rate on loans. 


\section{Parameterization}

We now want to see how well a version of the model parameterized to call report data on national banks predicts interest rates and bank note circulation. The strategy is the following. First, we match the national bank data to the theoretical constructs in the model. Then, we use the call report data and other information to calibrate the probability and cost parameters in the model. In the next section, we determine how well this calibrated model performs. The time period we use for comparison is 1882-1910. We choose 1882 as our starting point, because prior to the Act of July 12, 1882, banks with higher amounts of paid-in capital were more restricted in the amounts of notes they could issue than were banks with lower amounts of paid-in capital. This act made the restriction on note issuance a uniform 90 percent of paid-in capital for all banks. We end in 1910, because that is when our reliable data on national banks ends.

\section{A. The data}

The model constructs that we want to match to the national bank data are note issue, specie holdings, deposits, and the endowments of borrowers. To do this we have to decide at what point in the timing of the model the bank balance sheets are being observed. If we assume that banks' balance sheets are observed at the end of a period, then banks should not have specie on their books, since it was all paid out to young movers before the period ended. If we assume that the balance sheets are observed at the beginning of a period, then banks do not have any note liabilities, since they don't have to issue notes until households actually move later in the period. In actuality, national banks' balance sheets have both notes and specie at the same time. 
Our solution is to assume that bank balance sheets are observed shortly after the beginning of a period, so that the current young have had the opportunity to make their deposits and take out their loans. We also assume that banks have been able to adjust their specie reserves for the period to the desired level. However, we also assume old borrowers who have sold part of their endowment for bank notes have not yet had a chance to return to a bank to pay off their loans. Thus, notes outstanding correspond to an amount of loans made in the previous period.

With this assumption, we map the variables in our analysis into the items on the balances of national banks as:

Notes: $[B(t, j)+N(t, j)]$ "National Bank circulation." "State bank circulation" is not included since national banks could not issue more of these notes.

Specie: $[S(t)]$ "Fractional currency" + "Trade dollars" + "Specie" + "Legal-tender notes" + "5\% fund with Treasury" + "Due from U.S. Treasury" + "Due from reserve agents." The " $5 \%$ fund with Treasury" is included, because these were funds that national banks were required to deposit in specie with the U.S. Treasury as reserves for note issue, but which were also counted as reserves against deposits. The "Due from Treasury" is included because this is specie owed by the Treasury to national banks due to notes of other banks that they have sent in for redemption. The "Due from reserve agents" is included because these were counted as reserves against deposits, and represented funds that banks could call on to meet demands to redeem deposits.

Deposits: $[D(t)]$ Total liabilities and net worth less notes. Net worth is included as part of deposits, since national banks used their capital to fund loans. 
Endowment of borrowers: $[Y(t+1)]$ Total assets less specie and notes. Given the assumption about the timing of the observation of bank balance sheets, notes in circulation are equal to the unpaid loans of the previous cohort. Thus, subtracting specie and notes from total assets yields loans made to the current cohort, $L(t)$. The variable we want in the analysis, however, is the endowment of borrowers, $Y(t+1)=R(t) L(t)$, which involves the gross interest rate. Since the gross real interest rate is close to one, we ignore it and approximate $Y(t+1)$ as $L(t) .{ }^{8}$

In Figure 6, we plot these variables normalized by deposits, since such a normalization will be useful when we compare the predictions of the model with the data. Note that with this normalization, the fall in notes is still pronounced, but notes as a fraction of deposits (as we measure them) recovers only very slowly after hitting the minimum in 1890. Also note that the ratio of loans to deposits appears to fluctuate more than the ratio of notes to deposits or specie plus notes to deposits, but that is an illusion due to the different axes used for the different ratios.

\section{B. Parameters}

The next step is to calibrate the probabilities and costs. Our choices:

The probability of being in the good state: $\alpha(t, g)=0.9$. We choose the basic time period of the analysis as a year. Sprague 1910 identifies four years - 1884, 1890, 1893, and 1907 - in which financial disruptions occurred. Dwyer and Gilbert 1989 point out, however,

\footnotetext{
${ }^{8}$ During this period, national bank held deposits for the government - "United States deposits" and "Deposits U.S. disbursing agents" - which they had to back with government bonds - "Bonds for deposits" - as collateral. We have treated these like other deposits and loans in terms of our mapping from data to theory since they were not equal on bank balance sheets, so eliminating them would mean that our asset and liability measures would not add up.
} 
that there were only general restrictions of payments in New York City in 1893 and 1907. We come up with our value for $\alpha(g)$ by averaging these occurrences over the thirty-one years for which we have data.

The probability of moving in the good state: $\pi(t, g)=0.2$. Given that the gross interest rates during this period were close to one, we can obtain this probability as the ratio of notes plus specie to deposits from (1). From Figure 6, this value is approximately 0.2 over the period.

The probability of moving in the bad state: $\pi(t, b)=0.23$. We examine the sum of specie and notes normalized by deposits in the call reports near times that Sprague 1910 identifies as financial disruptions. These are marked by black diamonds in Figure 6 . We see that in two of these panics, these values were about 3 percentage points higher than at previous or subsequent call reports. Thus, we added 0.03 to $\pi(t, g)$ to get the calibrated value $\pi(t, b)$

The cost of issuing cheap notes: $c_{B}=1.01$ (1.005 after 1900). We take the cost of issuing cheap notes to be the tax on notes (1 percent per annum before 1900, one-half percent thereafter). Thus, in parameterizing the cost of issuing cheap notes we ignore any of the additional costs associated with note issue, such as those computed by the Comptroller of the Currency or by Champ 1990, because these costs were quite small.

The cost of issuing expensive notes: $c_{N}=1.05,1.13,1.20$ (less .005 after 1900). We assume that the cost of expensive notes is the tax plus some fixed cost times the number of times that notes were returned in a year. Although we have no way of calibrating this fixed cost precisely, the computations in Champ, Freeman, and Weber 1999 suggest that it is around 20 basis points. If this is correct, then our choices for $c_{N}$ correspond 
to expensive notes remaining in circulation for roughly two weeks, one week, and only a few days, respectively.

The restriction of the quantity of cheap notes that can be issued as a percentage of deposits: $\beta(t) / D(t)=0.06$. What we wanted was a value such that the restriction on issuing cheap notes would in general not be binding, but would bind occasionally, especially in times of panics. In Figure 6, we have plotted the line for $\beta(t) / D(t)=0.06$. We see that this value implies that banks were issuing expensive notes at the beginning and end of our sample period. They also issued them around the time of the crisis of 1893 and in 1897. For most of the rest of the time, however, only cheap notes were being issued. Thus, our choice for this parameter seems reasonable.

\section{Results}

We now see how well the parameterized version of our model fits with some actual data during the period. We keep the values of the parameters constant over the entire time period. The only exogenous variables that we allow to change are the endowments of borrowers and lenders. We do this to limit the number of free parameters. We first examine how the predictions of this calibrated model compare to the level and movements in the yields on long-term government bonds. Then we examine its predictions compared to the discounts on certified checks and the interest rates on call loans during periods of financial panics. Finally, we compare the level and movements in note circulation in the calibrated model with actual note circulation. 


\section{A. Government bond yields}

To see how well a calibrated version of our model performed versus actual government bonds yields, we computed $R(t)$ from our model for each call report date between 1882 and 1910. The actual government bond yields we use for comparison are those on the 4s of 1907 up to 1900 and those on the 2s of 1930 thereafter. We choose these bonds because they made up the largest component on those held by national banks during this period and they were the ones for which there was the least uncertainty about call dates that might be affecting yield computations. The call report data are for various days during a month; the government bond yield data are all end of month. For the comparisons we used the end of month observation closest to the call report date.

Comparisons of $R(t)$ from a calibrated version of the model with actual government bond yields over the period 1882 to 1910 for three different values of $c_{N}$ are shown in the table below.

\begin{tabular}{|c||c|c|c|c|}
\hline \multicolumn{1}{|c||}{} & \multicolumn{3}{c|}{ Model } & Actual \\
\cline { 2 - 5 } & $c_{N}=1.05$ & $c_{N}=1.13$ & $c_{N}=1.20$ & \\
\hline \hline Mean & 1.20 & 1.60 & 1.63 & 2.31 \\
\hline $\begin{array}{c}\text { Standard } \\
\text { Deviation }\end{array}$ & 0.273 & 0.414 & .0456 & 0.474 \\
\hline $\begin{array}{c}\text { Correlation } \\
\text { With Actual }\end{array}$ & 0.728 & 0.464 & 0.452 & \\
\hline
\end{tabular}

The results look quite good for the model. The means of the calibrated series are too low; they are below the mean of the government bond yields by approximately 70 to 110 basis points. This is not unexpected. Our choice for $c_{B}$ is very conservative since it does not include any other costs other than the tax that a national bank might incur due its note issuing activities. What is more important from our point of view is that the standard deviations of 
the computed and actual series are very close. Thus, we are able to explain the fluctuations in interest rates during this period.

Further, the correlations between the computed and actual series are all greater than 0.45, which indicates that the computed series tracks the actual series quite well. This is illustrated in Figure 7, where we show the comparison using $R(t)$ computed with a value of $c_{N}=1.13$ in the calibration. Specifically, the calibrated model captures the fall in government bond yields from 1882 to 1890, the rise from 1890 to the middle of 1893, and then the sharp fall in yields from then to 1900. The calibrated model also captures the increase in bond yields after 1900, although the figure shows that the model does a better job of tracking interest rate movements before 1900 than it does after that.

The figure further shows that the biggest interest misses are during three panics, those of 1884,1893 , and 1907 . These could be explained by the way we model deposits. Our model treats deposits as endowments that are not affected by which state occurs. However, if in actuality households withdraw deposits in bad states and this is captured by the data, it would lower $Y(t+1) / D(t)$ and therefore lower the calibrated model's $R(t)$.

We also compare our explanation of interest rate fluctuations with that in Champ, Smith, and Williamson 1996. To do so, we computed interest rates from our model under the assumption that note issuance was completely inelastic. We used three different values of the fixed level of note issue; $\beta(t) / D(t)=0.02,0.04,0.06$. (Values of $\beta(t) / D(t)>0.06$ force banks to issue too many notes in most periods, and interest rates are negative on average.) The results are shown in the table below. 


\begin{tabular}{|c||c|c|c|c|}
\hline \multicolumn{1}{|c||}{} & \multicolumn{3}{c|}{ CSW Model } & Actual \\
\cline { 2 - 4 } & $\beta(t) / D(t)=0.02$ & $\beta(t) / D(t)=0.04$ & $\beta(t) / D(t)=0.06$ & \\
\hline \hline Mean & 4.84 & 2.43 & 0.111 & 2.31 \\
\hline $\begin{array}{c}\text { Standard } \\
\text { Deviation }\end{array}$ & 1.19 & 1.17 & 1.15 & 0.474 \\
\hline $\begin{array}{c}\text { Correlation } \\
\text { With Actual }\end{array}$ & 0.150 & 0.150 & 0.149 & \\
\hline
\end{tabular}

When note issue is completely inelastic at $\beta(t) / D(t)=0.04$, the mean of the computed interest rate series are closer to the actual mean than are the interest rates from our model. However, for other values, the means are either much too high or much too low. Further, for all $\beta(t) / D(t)$, the completely inelastic model produces interest rate fluctuations that are far larger than the actual fluctuations, and the correlations between the computed interest rates and actual interest rates are lower than those from our model. Thus, the evidence indicates that our model outperforms the completely inelastic note issue model.

\section{B. Note circulation}

Next, we see how well the calibrated version of our model predicts the level and movements of actual note issue during this period. Our method is similar to that used for the long term government bond yields, with one major exception. The interest on loans in the model economy is invariant to the state of the economy; banks' note issuance is not. Thus, we have to make an assumption about when the actual economy was in the bad state. Sprague 1910 designates four periods in which financial disruptions occurred: the panic of May 1884 (Gorton 1988 lists this as occurring in June), the financial stringency in November 1890, the crisis from May through September 1893, and the crisis from October through December 1907. We assume that the actual economy was in the bad state in those periods around Sprague's four financial disruptions and in the good state otherwise. 
Comparisons of $[B(t, j)+N(t, j)] / D(t)$ from a calibrated version of the model with actual values over the period 1882 to 1910 for the same three values of $c_{N}$ used above are shown in the table below.

\begin{tabular}{|c|c|c|c|c|c|}
\hline & \multicolumn{4}{|c|}{ Model } & \multirow{2}{*}{ Actual } \\
\hline & $c_{N}=1.05$ & $c_{N}=1.13$ & $c_{N}=1.20$ & $c_{N}=c_{B}$ & \\
\hline Mean & 0.045 & 0.042 & 0.042 & 0.047 & 0.073 \\
\hline $\begin{array}{l}\text { Standard } \\
\text { Deviation }\end{array}$ & 0.0088 & 0.0072 & 0.0069 & 0.0096 & 0.0328 \\
\hline $\begin{array}{c}\text { Correlation } \\
\text { With Actual }\end{array}$ & 0.294 & 0.331 & 0.305 & 0.310 & \\
\hline
\end{tabular}

The results do not look as good as those for interest rates. The means of the calibrated series for note issues are only about half those of the actual series. Further, the standard deviations of note issue for the calibrated model are less than one-fourth as large as the standard deviation of actual note issues. Thus, the calibrated model demonstrates even more inelasticity of note issue than was actually the case. Lastly, the correlation between the model's predictions and actual is quite low.

The difficulties that the model has predicting note circulation is illustrated in Figure 8, where we show the comparison using $[B(t, j)+N(t, j)] / D(t)$ computed with a value of $c_{N}=1.13$ in the calibration. The calibrated model badly misses the fall in note circulation from 1882 to 1890 , although it does capture to some extent the rise in note circulation after 1900. We checked the extent to which the early miss in circulation was the reason that the model appeared to do so poorly. When the period from 1882 to 1890 is eliminated from the comparison, the difference between the means of the calibrated model and the actual series is reduced, but the actual is still larger than the model. The standard deviation of actual note circulation falls dramatically, and the standard deviation of actual and model become 
virtually the same. However, the correlation between actual and model falls to below 0.1, indicating that there seems to be no relationship between actual note circulation and that predicted by the model.

As a final exercise, we used the model to determine how much more elastic note issuance would have had to have been in order to eliminate interest rate fluctuations (other than those due to changes in the tax on notes) during this period. The result is given in the column of the table above labeled " $c_{N}=c_{B}$ ". We find that mean note issue rises slightly to 0.47 . The standard deviation of note issue becomes 0.0096 . Thus, if we consider the elasticity of note issuance to be its standard deviation, our model says that an increase in note elasticity of between 8 and 30 percent would have been sufficient to eliminate interest rate fluctuations during this period. The elasticity issue can be viewed in another way. We computed the value of $\beta(t) / D(t)$ that would be necessary for interest rates to be equal to the tax rate on notes. It turned out to be $\beta(t) / D(t)=0.1$. In other words, our model indicates that if banks had been able to circulate notes equal to 10 percent of total liabilities plus net worth less notes rather than just 6 percent as per our calibration, then interest rates would have been equal to the tax on note circulation.

\section{Interest rates during financial disruptions}

Finally, we examine how well a calibrated version of our model does explaining the interest rates paid to depositors during periods in which there were financial disruptions. There is no direct evidence on the interest rates paid to depositors under the National Banking System. However, we can make some inferences about how these rates moved and how high they might have been, at least during periods of financial disruption. 
Before the establishment of the Federal Reserve System in 1913, when banks suspended payments on deposits, as they did in 1893 and 1907, they did not close their doors for business. They continued to go about the normal business of banking, with the exception that they did not pay out specie for deposits. However, they would certify checks for their depositors. This basically made the check a liability of the bank and meant that the bank would pay the check when the suspension of payments ended if the bank were solvent at the time. According to Sprague 1910, these certified checks circulated and could be discounted for specie. Sprague 1910 does not present evidence of there being any discounts on certified checks for the panic of 1884 and the financial stringency 1890 . However, for the crisis of 1893 he says that discounts on certified checks were mostly between 1 and 2 percent, with some of the discounts reaching 4 percent. For the crisis of 1907 , he says that discounts were most in the range of $3 / 4$ to 2-1/2 percent, with again some reaching the level of 4 percent. We interpret the fact that certified checks could be discounted against specie during periods of financial disruption as meaning that movers received less than a dollar for each dollar of their deposits during such periods.

Drawing inferences about the interest rates paid to nonmovers is more difficult. Our approach is to use the interest rate on call loans to provide some information about interest rates paid to nonmovers. Call loans were loans made to individual based upon stocks as security. They were referred to as call loans, because they were payable when demanded by the bank. It is well known that the interest rates on call loans tended to increase sharply and to be well above government bond yields during periods of financial disruption. We think that the interest rates on such loans provide some information about the interest rate that nonmover depositors might have been able to earn, because presumably such households had 
the option of withdrawing their funds from banks and making short-term loans directly to other agents. Although they may not have been able to earn the interest rates on call loans, we think the returns on such alternatives would tend to move with call money rates. We interpret the fact that call money rates rose sharply during financial disruptions as meaning that the interest rate paid to nonmovers rose sharply above the rate of interest on loans during periods of financial disruption. ${ }^{9}$

To see if the calibrated version of the model delivers predictions consistent with these broad facts, we compute the interest rates paid to movers and nonmovers for our model designating the periods around Sprague's four periods of financial disruptions as periods in which the bad state actually occurred. The results are shown in Figure 9. From the figure we see that the interest rates paid to movers are usually around one percent or less. However, in the periods of financial disruption, these interest rates fall sharply and become negative, consistent with discounts on certified checks. Interest rates paid to nonmovers are usually very slightly below the interest rate on loans, but in periods of financial disruption, they rise sharply and are above the interest rate on loans during these periods. This is consistent with increased call loan rates during financial disruptions.

We can also examine how well the magnitudes of interest rates for movers and nonmovers during panics periods from our calibrated model match those observed in actuality. Interest rates paid to movers in panics periods are about a negative 7 or 8 percent in the calibrated model. As mentioned above, in actuality the discounts on certified checks were usually only 1 or 2 percent, although sometimes they got as high as 4 percent. Thus, it

\footnotetext{
${ }^{9}$ Here we differ from Champ, Smith, and Williamson 1994. They map call loan rates into $R(t)$ rather than into $R^{n}(t, j)$ as we are doing. We prefer our mapping because government bonds more closely resemble loans in our model. Specifically, government bonds were safe financial securities and had a fixed term to maturity.
} 
would seem that the calibrated model overpredicts the losses to movers in periods of financial disruption. However, it must be remembered that what is being reported for certified checks is the discount, the immediate loss that the holder of the certified check suffers when attempting to convert it to specie. The variable reported for the calibrated model is an interest rates, the amount that the mover receives at the end of the period as a percentage of the amount deposited. The time period in the calibration is assumed to be a year. The time period over which the discount on certified checks was actually realized by households during the period we are considering may have been much shorter. Hence, the differences between the calibrated model and the discounts reported by Sprague would be of the same order of magnitude if the discounts were realized over six weeks to half a year. This does not seem unreasonable. Although the financial disruptions of 1884 and 1890 only lasted a few weeks, the one in 1893 lasted approximately five months and the Panic of 1907 lasted approximately three months.

To see how well the calibrated model's interest rates for nonmovers matches the data, we plot monthly averages of call rates for 1890 to 1910 in Figure 10. Interest rates for nonmovers in panic periods in the calibrated model are around 5 percent. Average monthly call loan rates are far higher during periods of financial disruption. In particular, they are over 10 percent during the crisis of 1890 and over 20 percent during the Panic of 1907 . However, the interest rates in the calibrated model are yearly rates; call loan rates are for demand loans, which would be of a much smaller duration. Thus, if we were to compare the interest rates paid to nonmovers from the calibrated model to call loan rates averaged over a long period of time, the difference in magnitudes would not be that great. For example, in Figure 10, we also plot twelve-month moving averages of call loans rates. The figure shows that 
during the periods of financial disruption, these moving averages are close to the 5 percent rates from the calibrated model.

\section{Conclusion}

The so-called National Bank note paradox is that a large and persistent arbitrage opportunity seemed to go unexploited from the time the National Banking System was established until the establishment of the Federal Reserve System. This unexploited arbitrage opportunity was that the yield on government bonds was consistently above the cost of issuing national bank notes.

Several authors have attempted to explain this paradox. In this paper, we focus on the paper by Champ, Smith, and Williamson 1996. They have attempted to explain this paradox by arguing that national bank note issue was inelastic due to "the mechanics of note issue." We agree with them that national bank note issue did not fluctuate much over short periods of time, but we point out that note displayed large secular fluctuations. Thus, we disagree that whatever inelasticity there was in national bank issue was due to exogenous factors. Instead, we think that there were times when national banks could rationally expected that any additional notes they might issue would be quickly presented for redemption. Because there were costs associated with note redemption that were independent of the time that notes were in circulation, these notes were more expensive to issue than notes that would be in circulation for longer periods.

Thus, we built a model in which national banks could issue two types of notes cheap notes and expensive notes - and in which there was an exogenous upper bound on the quantity of cheap notes that can be issued. We found that such model implies that, at least 
for certain parameter values, interest rates can be above the cost of issuing cheap notes and that can fluctuate in response to changes in endowments. When we took a calibrated version of the model to data, we found that it did quite well. It was able to predict both the level of and changes in the yields on long term-government bonds during the period. However, it did not do as well in accounting for fluctuations in note issuance. The model displayed more note inelasticity than the actual data. 


\section{References}

Bell, Spurgeon. 1912. Profit on national banknotes. American Economic Review 2 (March): $38-60$.

Cagan, Phillip. 1963. The first fifty years of the national banking system. In Banking and Monetary Studies, Deanne Carson, ed. 15-42. Homewood, Ill.: Richard D. Irwin. . 1965. Determinants and Effects of Changes in the Stock of Money, 1875-1960.

New York: Columbia University Press.

Cagan, Phillip, and Anna J. Schwartz. 1991. The national bank note puzzle reinterpreted. Journal of Money, Credit, and Banking 23 (August): 293-307.

Champ, Bruce. 1990. The underissuance of national banknotes, 1875-1913. University of Minnesota Ph.D. thesis.

Champ, Bruce, Scott Freeman, and Warren E. Weber. 1999. Redemption costs and interest rates under the U.S. national banking system. Journal of Money, Credit, and Banking 31 (August): 568-89.

Champ, Bruce, Bruce D. Smith, and Stephen D. Williamson. 1996. Currency elasticity and banking panics: Theories and evidence. Canadian Journal of Economics 29: 4 (November): 828-64.

Champ, Bruce, Neil Wallace, and Warren E. Weber. 1992. Resolving the national bank note paradox. Federal Reserve Bank of Minneapolis Quarterly Review 16 (Spring): 13-21. . 1994. Interest rates under the U.S. national banking system. Journal of Monetary Economics 34 (December): 343-58.

Dwyer, Gerald P. Jr.and Alan R. Gilbert. 1989. Bank runs and private remedies. Federal 
Reserve Bank of St. Louis Review 71 (May-June): 43-61.

Friedman, Milton, and Anna J. Schwartz. 1963. A Monetary History of the United States, 1867-1960. Princeton: Princeton University Press.

Goodhart, C.A.E. 1965. Profit on national bank notes, 1900-1913. Journal of Political Economy 83 (October): 516-22.

Gorton, Gary. 1988. Banking prices and business cycles. Oxford Economic Papers 40 (December) 751-81.

James, John A. 1976. The conundrum of the low issue of national bank notes. Journal of Political Economy 86 (April): 359-67.

Kuehlwein, Michael. 1992. The national bank note controversy reexamined. Journal of Money, Credit, and Banking 24 (February): 111-26.

Sprague, O.M.W. 1910. A History of Crises under the National Banking System. Washington: U.S. Government Printing Office.

Weber, Warren E. 2000. Disaggregated call reports for U.S. National Banks, 1880-1910. Research Department, Federal Reserve Bank of Minneapolis. http:\\res.mpls.frb.fed.us \} research $\backslash$ economists $\backslash$ wewproj.html. 


\section{Appendix}

Proof of the Proposition 3.3 (Existence)

Proof: By Assumption P, $S(t)>0, B(t, j)>0$. From the Lemma we know that $R^{m}(t, j)$ and $R^{n}(t, j)$ will be positive and real and $R(t)$ will be positive if $R(t)$ is real. Thus, it remains to show that $R(t)$ is real.

For the cases in which $B(t, b)<\beta(t)$ and $N(t, g)>0$, that $R(t)$ is real can be seen by solving the conditions for equilibrium. We consider the other cases one at a time. For convenience we drop all time subscripts. Rewrite (9) as

$$
\begin{aligned}
& R^{3}\left[\alpha R^{m}(b) R^{n}(g) R^{n}(b)+(1-\alpha) R^{m}(g) R^{n}(g) R^{n}(b)\right] \\
= & R^{4}\left[\alpha R^{m}(g) R^{m}(b) R^{n}(b)+(1-\alpha) R^{m}(g) R^{m}(b) R^{n}(g)\right]
\end{aligned}
$$

Let

$$
\begin{aligned}
\theta_{1} & =c_{B}+\tilde{y} \\
\theta_{2} & =-c_{B} \tilde{y} \\
\nu_{1} & =c_{N}+\tilde{y}+\left(c_{N}-c_{B}\right) \tilde{\beta} \\
\nu_{2} & =-c_{N} \tilde{y} \\
\mu_{j} & =\frac{1}{1-\pi(j)}\left(\tilde{y}-c_{B} \tilde{\beta}\right), \quad j=g, b \\
\lambda_{1 j} & =\frac{1}{\pi(j)}(1+\tilde{\beta}), \quad j=g, b \\
\lambda_{2 j} & =-\frac{1}{\pi(j)} \tilde{y}, \quad j=g, b
\end{aligned}
$$


Then

$$
\begin{aligned}
& R R^{n}(j)= \begin{cases}\theta_{1} R+\theta_{2}, & 0<B(j)<\beta \\
\mu_{j} R, & B(j)=\beta, N j)=0 \quad j=g, b \\
\nu_{1} R+\nu_{2}, & N(j)>0\end{cases} \\
& R R^{m}(j)= \begin{cases}c_{B} R R^{n}(j), & 0<B(j)<\beta \\
\lambda_{1 j} R+\lambda_{2 j}, & B(j)=\beta, N j)=0 \quad j=g, b \\
c_{N} R R^{n}(j), & N(j)>0\end{cases}
\end{aligned}
$$

We now prove the proposition by demonstrating the existence of equilibrium for each possible note issue case that can occur. It turns out that for all cases, the solution for $R$ is a quadratic equation. Thus, we check to determine whether $\sqrt{b^{2}-4 a c}$ is positive.

Case II: $B(g)<\beta, B(b)=\beta, N(b)=0$.

Substituting for $R R^{m}(j)$ and $R R^{n}(j)$, multiplying by $c_{B} /\left[R\left(\theta_{1}+\theta_{2}\right)\right]$, and collecting terms yields the quadratic equation

$$
\begin{aligned}
0= & {\left[\alpha \lambda_{12} \mu_{2}+(1-\alpha) \theta_{1} \lambda_{12}\right] R^{2}+\left\{\alpha \mu_{2}\left(\lambda_{22}-c_{B} \lambda_{12}\right)+(1-\alpha)\left[\theta_{1}\left(\lambda_{22}-\mu_{2}\right)+\theta_{2} \mu_{2}\right]\right\} R } \\
& -\alpha c_{B} \lambda_{22} \mu_{2}+(1-\alpha) \theta_{2}\left(\lambda_{22}-\mu_{2}\right)
\end{aligned}
$$

Substituting, we find that

$$
b^{2}-4 a c=\left\{\alpha \mu_{12}\left(c_{B} \lambda_{12}+\lambda_{22}\right)+(1-\alpha)\left[\theta_{1}\left(\lambda_{12}-\mu_{22}\right)-\theta_{2} \lambda_{12}\right]\right\}^{2}+4 \alpha(1-\alpha) \lambda_{12}\left(c_{B} \mu_{2}\right)^{2}
$$

which is positive since $\lambda_{12}>0$. 
Case III: $B(g)<\beta, B(b)=\beta, N(b)>0$.

Substituting for $R R^{m}(j)$ and $R R^{n}(j)$, multiplying by $c_{B} c_{N} /\left[\left(\theta_{1} R+\theta_{2}\right)\left(\nu_{1} R+\nu_{2}\right)\right]$, and collecting terms yields the quadratic equation

$$
0=\left[\alpha \nu_{1}+(1-\alpha) \theta_{1}\right] R^{2}+\left[\alpha\left(\nu_{2}-c_{B} \nu_{1}\right)+(1-\alpha)\left(\theta_{2}-c_{N} \theta_{1}\right)\right] R-\left[\alpha c_{B} \nu_{2}+(1-\alpha) c_{N} \theta_{2}\right]
$$

Substituting, we find that

$$
b^{2}-4 a c=\left[\alpha\left(\nu_{1}+c_{B} \nu_{2}\right)+(1-\alpha)\left(\theta_{2}+c_{N} \theta_{1}\right)\right]^{2}+4 \alpha(1-\alpha) \tilde{y}\left(c_{N}-c_{B}\right)\left(\tilde{y}-c_{B} \tilde{\beta}\right)
$$

which is positive since $\left(\tilde{y}-c_{B} \tilde{\beta}\right)>0$.

Case IV: $B(g)=\beta, B(b)=\beta, N(g)=N(b)=0$.

Substituting for $R R^{m}(j)$ and $R R^{n}(j)$, multiplying by $R^{2}$, and collecting terms yields the quadratic equation

$$
\begin{aligned}
0= & {\left.\left[\alpha \mu_{2}+(1-\alpha) \mu_{1}\right] \lambda_{11} \lambda_{12} R^{2}+\left\{2\left[\alpha \mu_{2}+(1-\alpha) \mu_{1}\right] \lambda_{12} \lambda_{21}-\mu_{1} \mu_{2}\left[\alpha \lambda_{12}+(1-\alpha) \lambda_{11}\right)\right]\right\} R } \\
& +\left[\alpha \mu_{2}+(1-\alpha) \mu_{1}\right] \lambda_{21} \lambda_{22}-\mu_{1} \mu_{2}\left[\alpha \lambda_{22}+(1-\alpha) \lambda_{21}\right]
\end{aligned}
$$

Substituting, we find that

$$
b^{2}-4 a c=\left\{\mu_{1} \mu_{2}\left[\alpha \lambda_{12}+(1-\alpha) \lambda_{11}\right]\right\}^{2}>0 .
$$

Case V: $B(g)=\beta, B(b)=\beta, N(g)=0, N(b)>0$. 
Substituting for $R R^{m}(j)$ and $R R^{n}(j)$, multiplying by multiplying by $c_{N} /\left[R\left(\nu_{1}+\nu_{2}\right)\right]$, and collecting terms yields the quadratic equation

$$
\begin{aligned}
0= & {\left[\alpha \lambda_{12} \mu_{2}+(1-\alpha) \theta_{1} \lambda_{12}\right] R^{2}+\left\{\alpha \mu_{2}\left(\lambda_{22}-c_{B} \lambda_{12}\right)+(1-\alpha)\left[\theta_{1}\left(\lambda_{22}-\mu_{2}\right)+\theta_{2} \mu_{2}\right]\right\} R } \\
& -\alpha c_{B} \lambda_{22} \mu_{2}+(1-\alpha) \theta_{2}\left(\lambda_{22}-\mu_{2}\right)
\end{aligned}
$$

Substituting, we find that

$b^{2}-4 a c=\left\{\alpha\left[\nu_{1}\left(\lambda_{21}-\mu_{2}\right)-\nu_{2} \lambda_{12}\right]+(1-\alpha) \mu_{1}\left(c_{N} \lambda_{11}+\lambda_{21}\right)\right\}^{2}+4 \alpha(1-\alpha) \lambda_{11}\left(c_{N}-c_{B}\right)\left(c_{N} \mu_{1}\right)^{2} \tilde{\beta}$

which is positive since $\lambda_{11}>0$.

\section{Proof of Proposition 3.3 (Positivity)}

Proof: We know from the loan market clearing condition (13) that $S(t) / D(t)=1-$

$\frac{Y(t+1)}{R(t) D(t)}$. The right hand side of this equality cannot be smaller than $1-\frac{Y(t+1)}{c_{B} D(t)}$ since $c_{B}$ is a lower bound on $R(t)$, by Property (2) of the Lemma. So, by the assumption, $S(t)>0$.

From the resource constraint of the banks (3), we have

$$
B(t, g)=\pi(t, g) R^{m}(t, g) D(t)-S(t)-N(t, g)
$$

But we know that $B(t, g)=\beta>0$ whenever $N(t, g)>0$. Therefore we are only interested in the case where $N(t, g)=0$. Substituting for $S(t)$ in (14), we can express $B(t, g)$ as

$$
B(t, g) / D(t)=\pi(t, g) R^{m}(t, g)-1+\frac{Y(t+1)}{R(t) D(t)} .
$$


Since we want $B(t, g)>0$ we need to find a lower bound on $R^{m}(t, g)$. Let us show that $R^{m}(t, g) \geq c_{B} / c_{N}$. By way of contradiction, suppose that this is not true. Then using Property (4) of the Lemma, we have that $c_{B}=c_{N} \frac{c_{B}}{c_{N}}>c_{N} R^{m}(t, j) \geq R^{n}(t, j)$. But this inequality contradicts Property (6) of the Lemma. Hence,

$$
B(t, g)>\pi(t, g) \frac{c_{B}}{c_{N}}-1+\frac{Y(t+1)}{R(t) D(t)}>\pi(t, g) \frac{c_{B}}{c_{N}}-1+\frac{Y(t+1)}{c_{N} D(t)}>0
$$

where the last inequality follows from $S(t)>0$. 
Figure 1 -- Government Bond Yields, 1882-1913

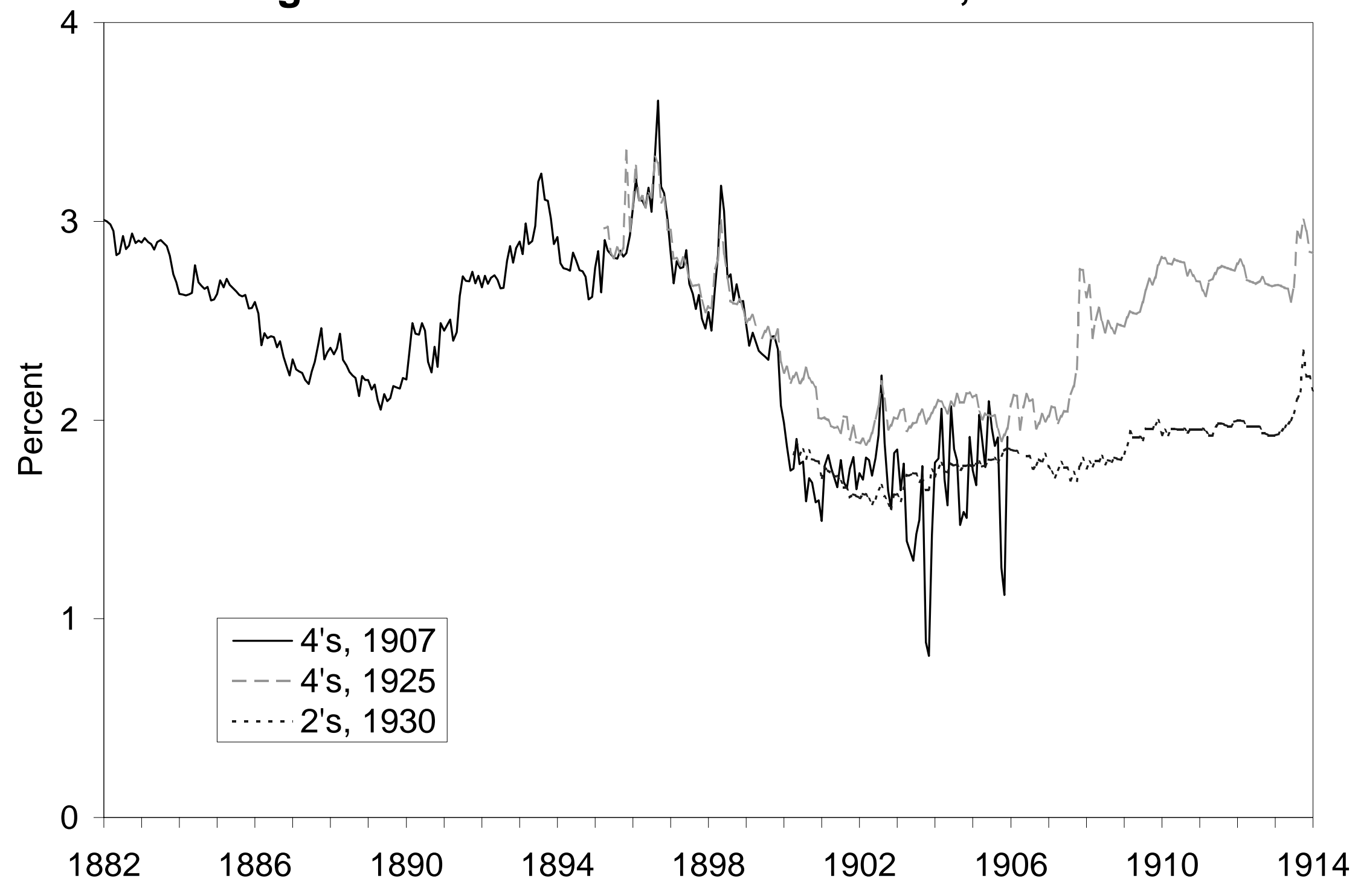


Figure 2 -- Percentage changes in National Bank Note Circulation, 1882 - 1910

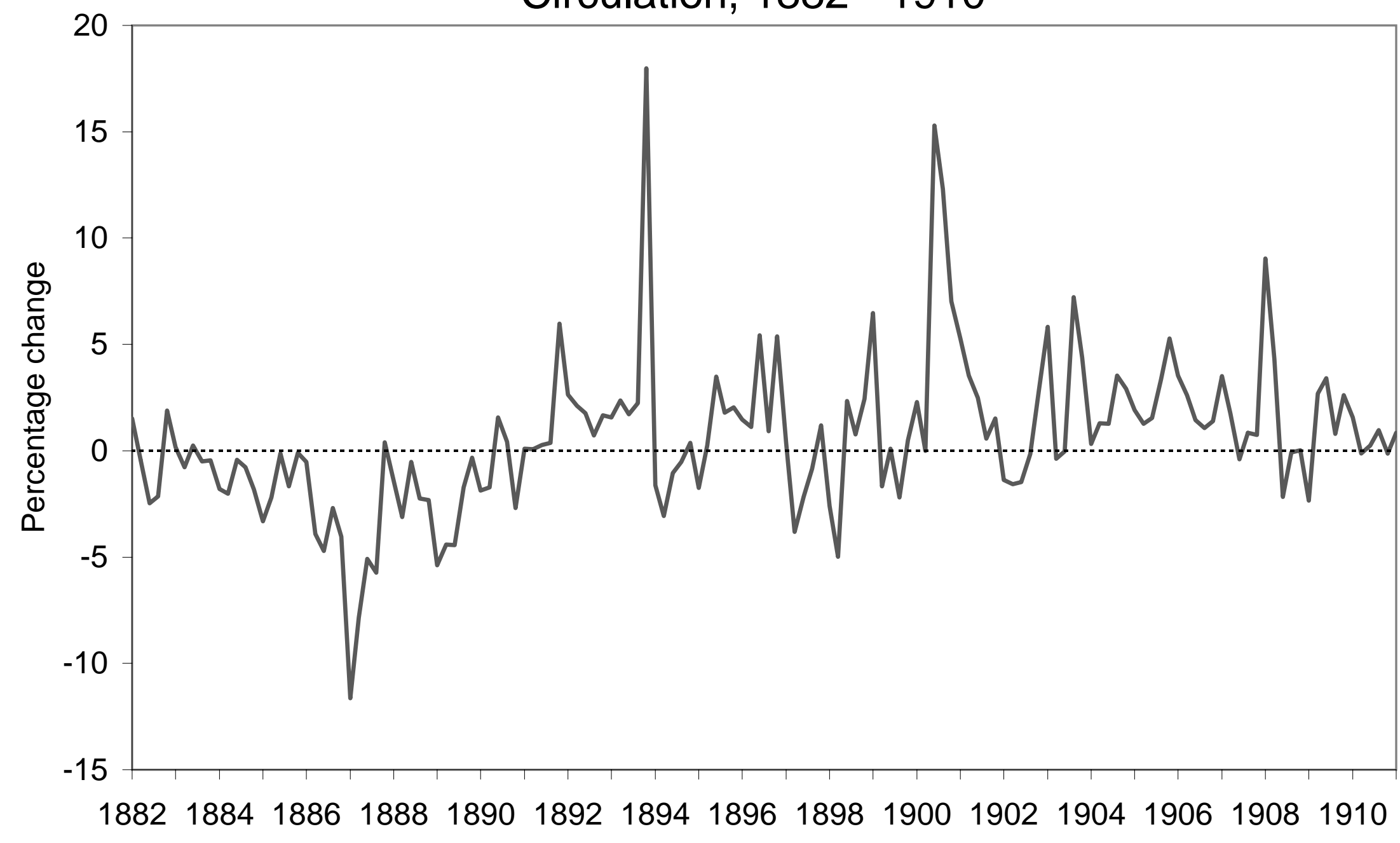


Figure 3 -- National Bank Note Circulation, 1882 - 1910

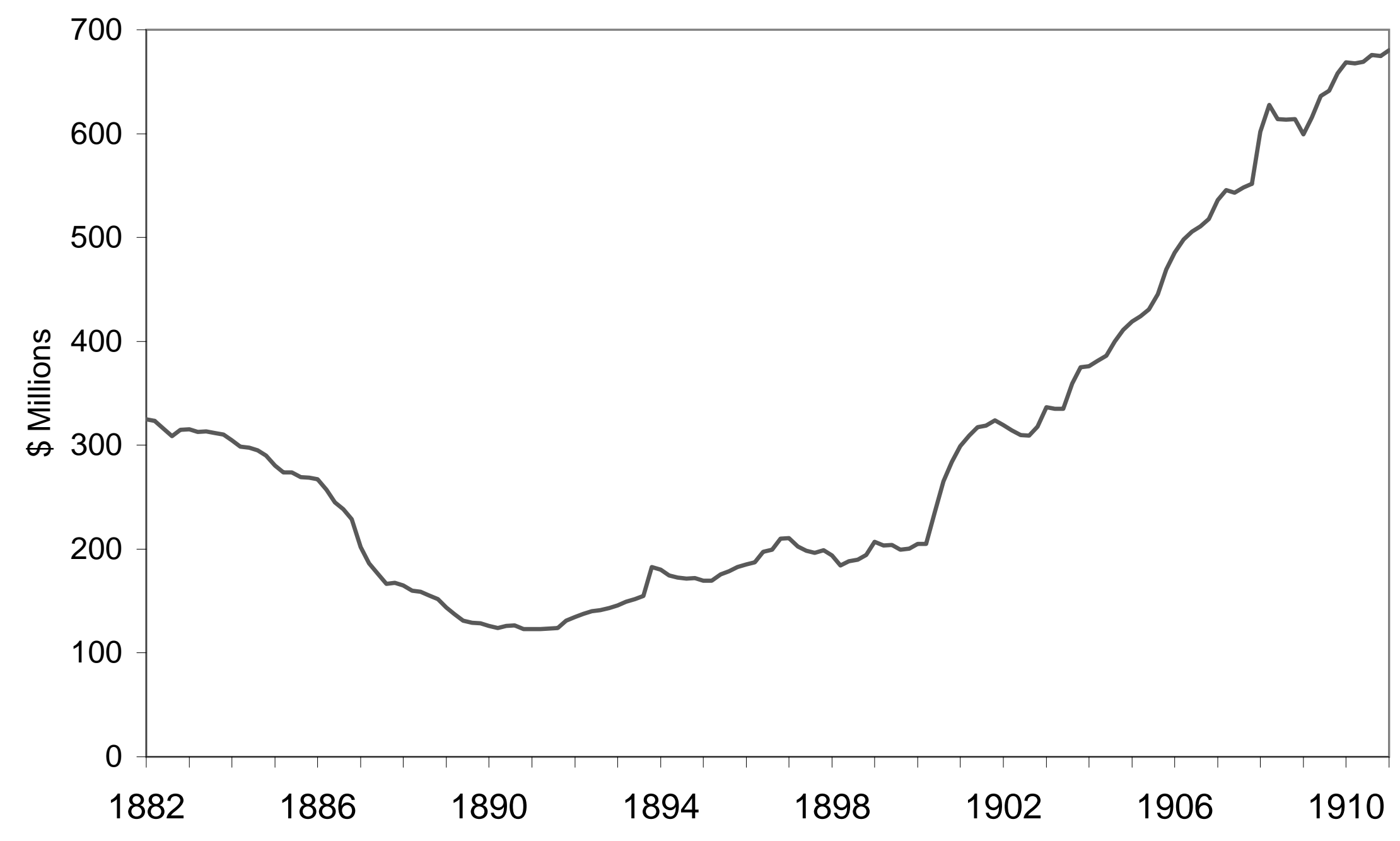


Figure 4 - Model Timing

\section{Old}

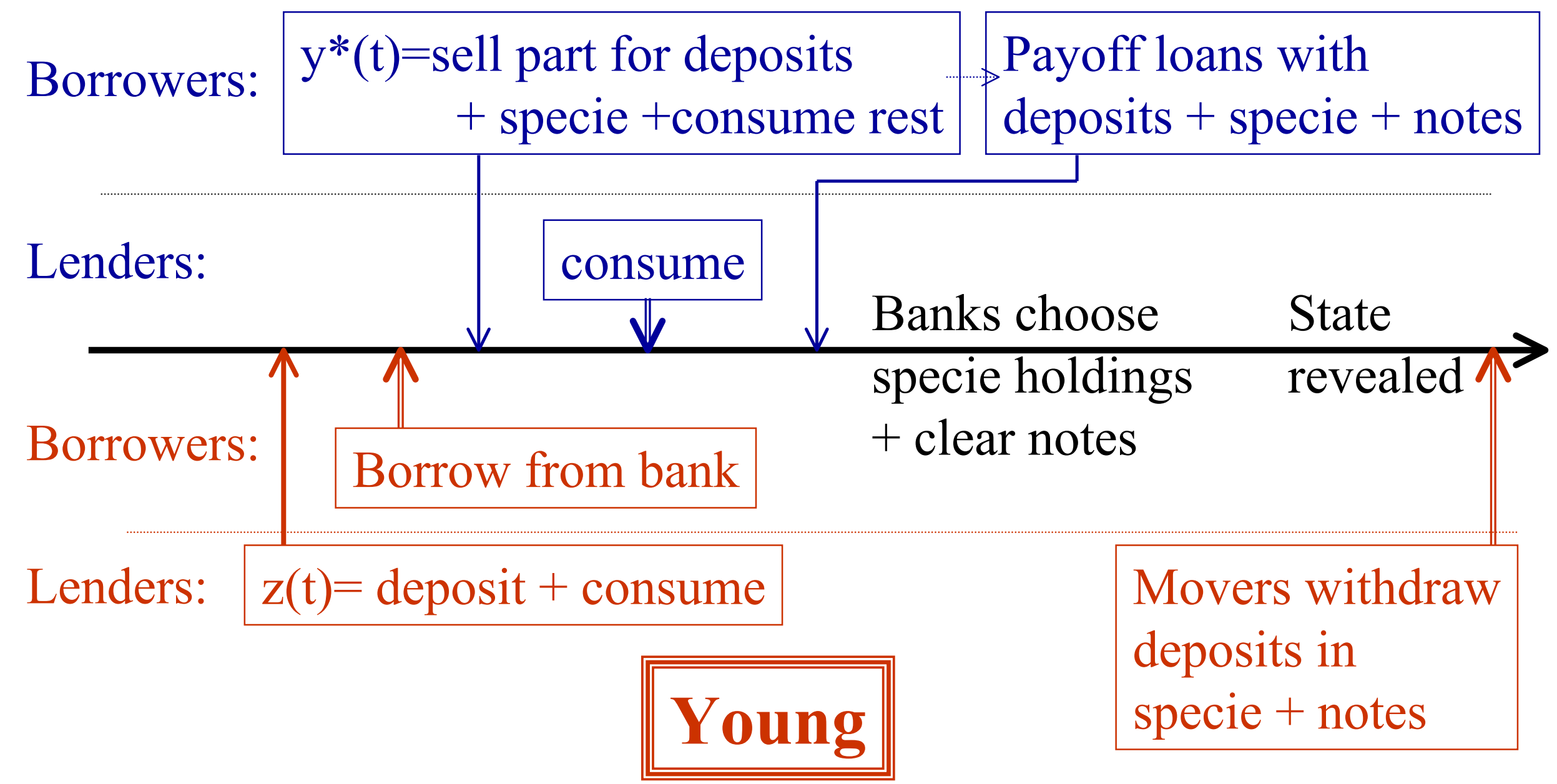


Figure 5 -- Representative Model Interest Rates

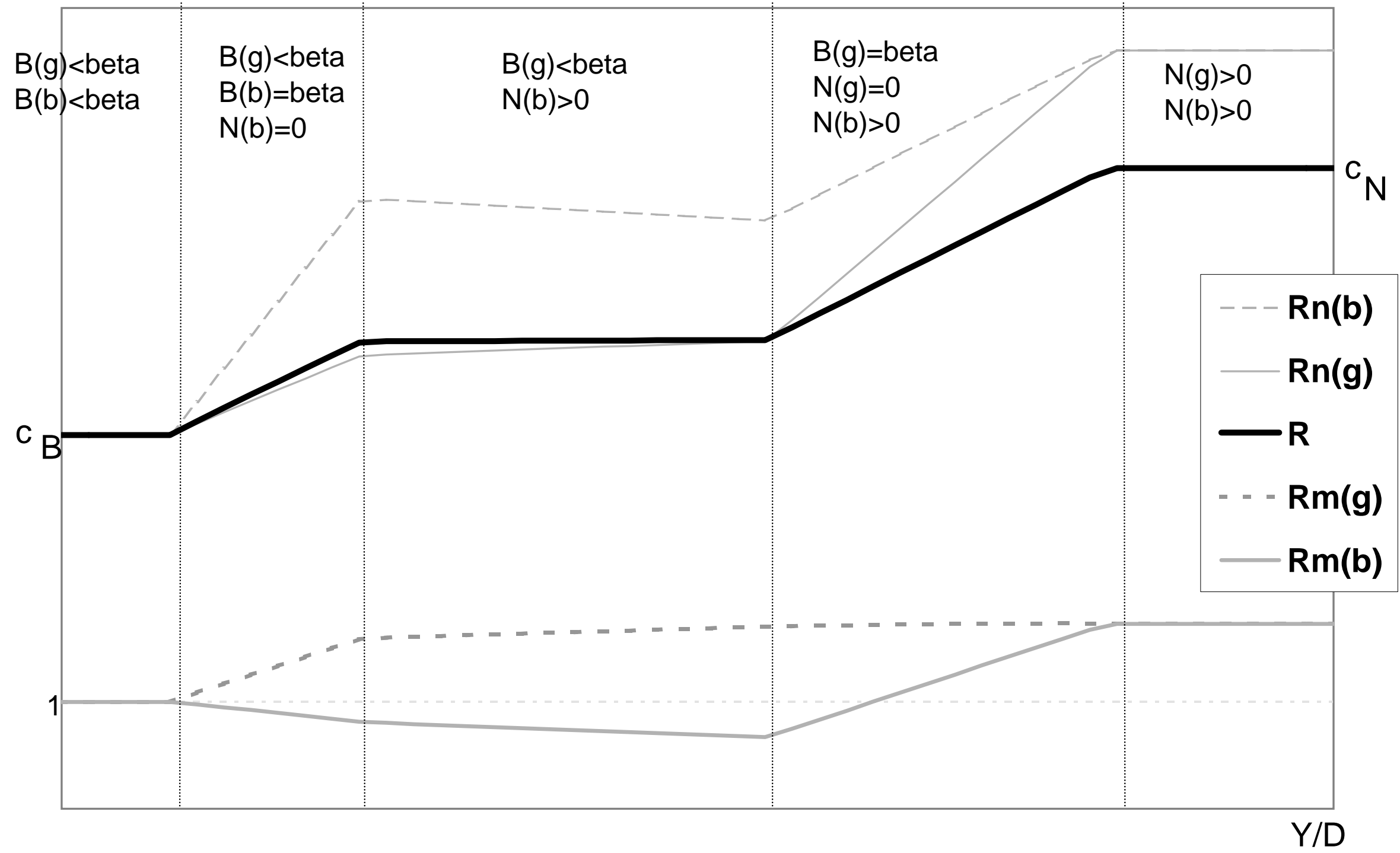


Figure 6 -- Ratios of model variables, 1882 - 1910

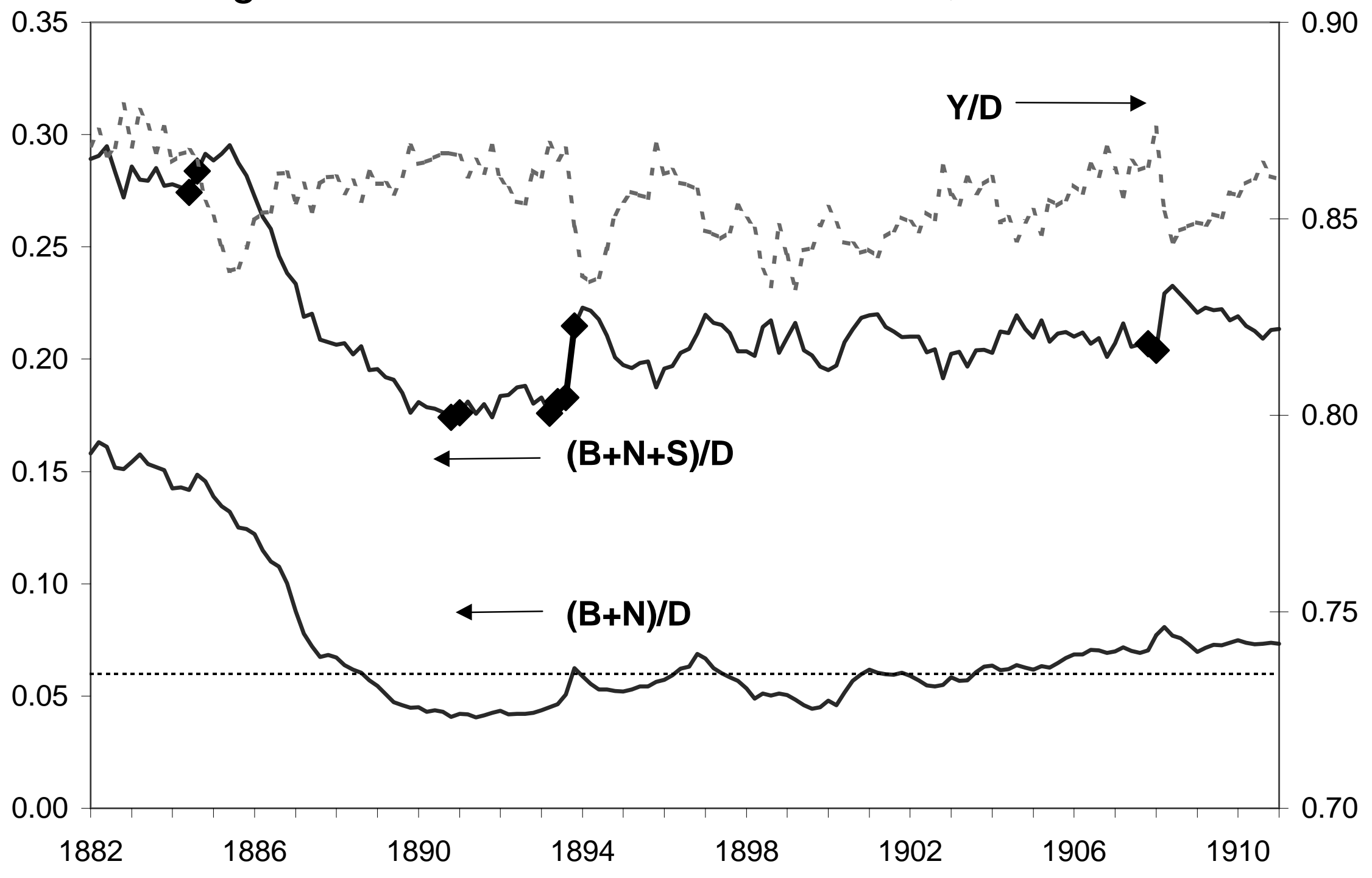


Figure 7 -- Interest rate comparisons

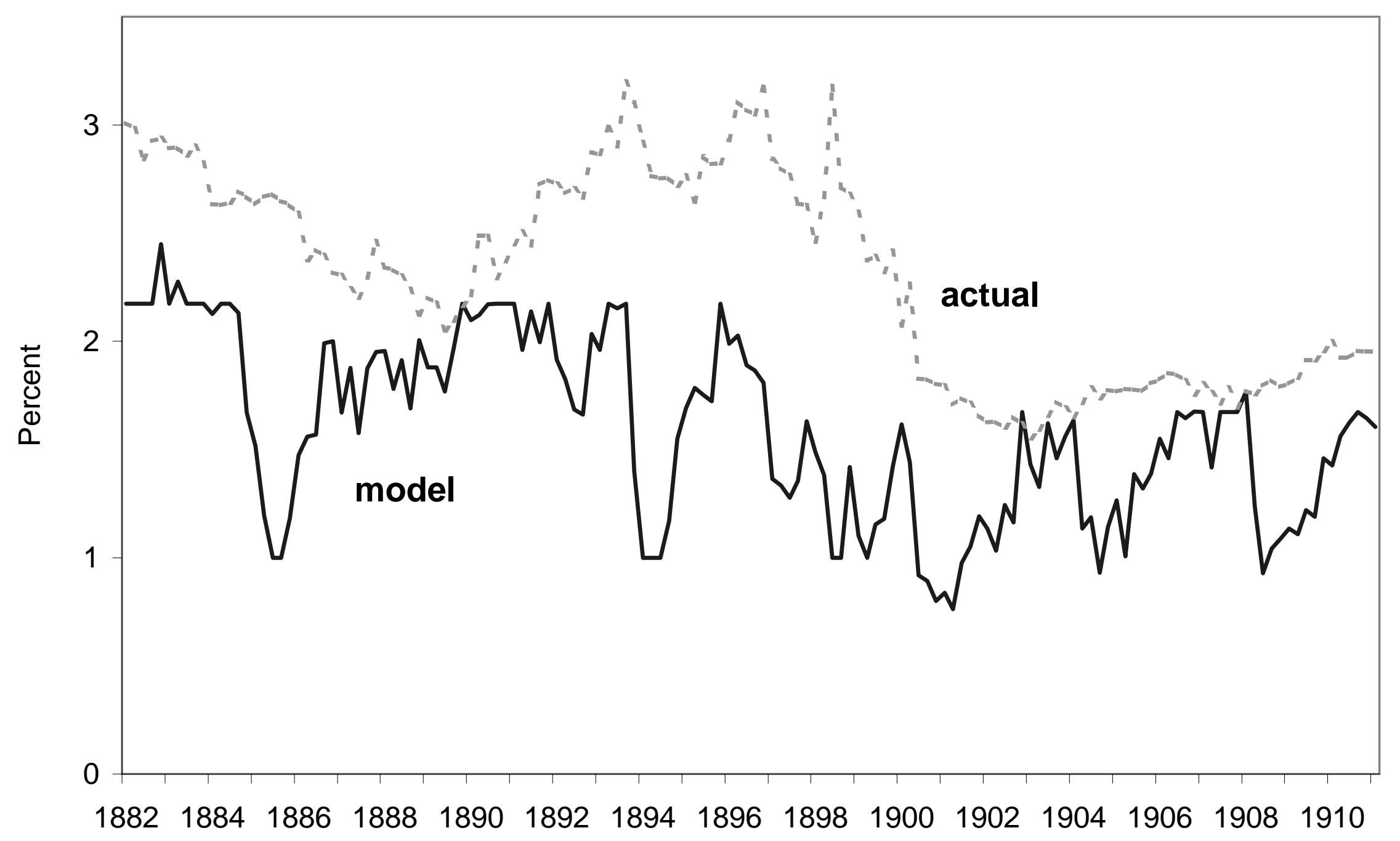


Figure 8 -- Note circulation comparisons

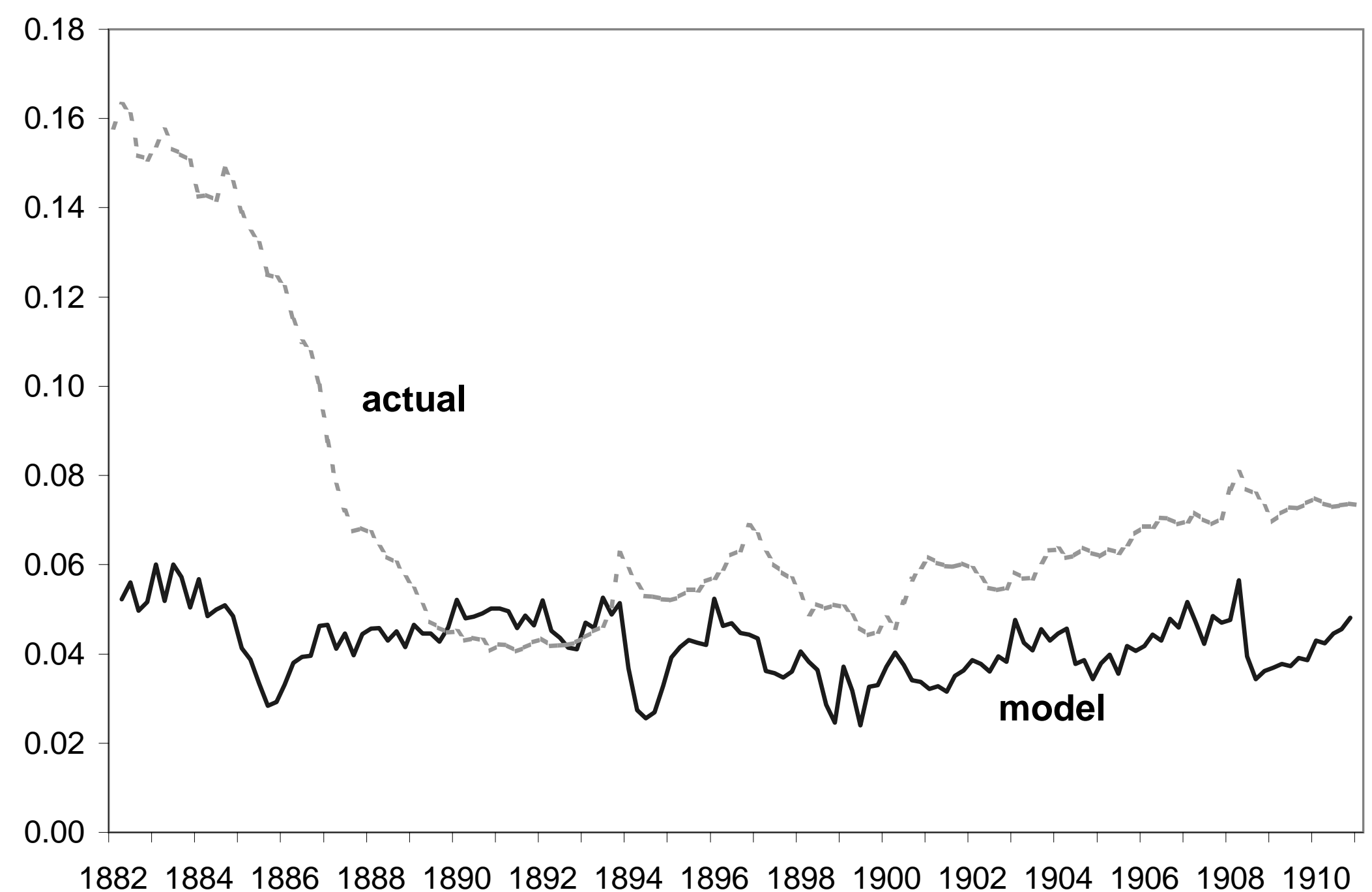


Figure 9 -- Predicted interest rates from model

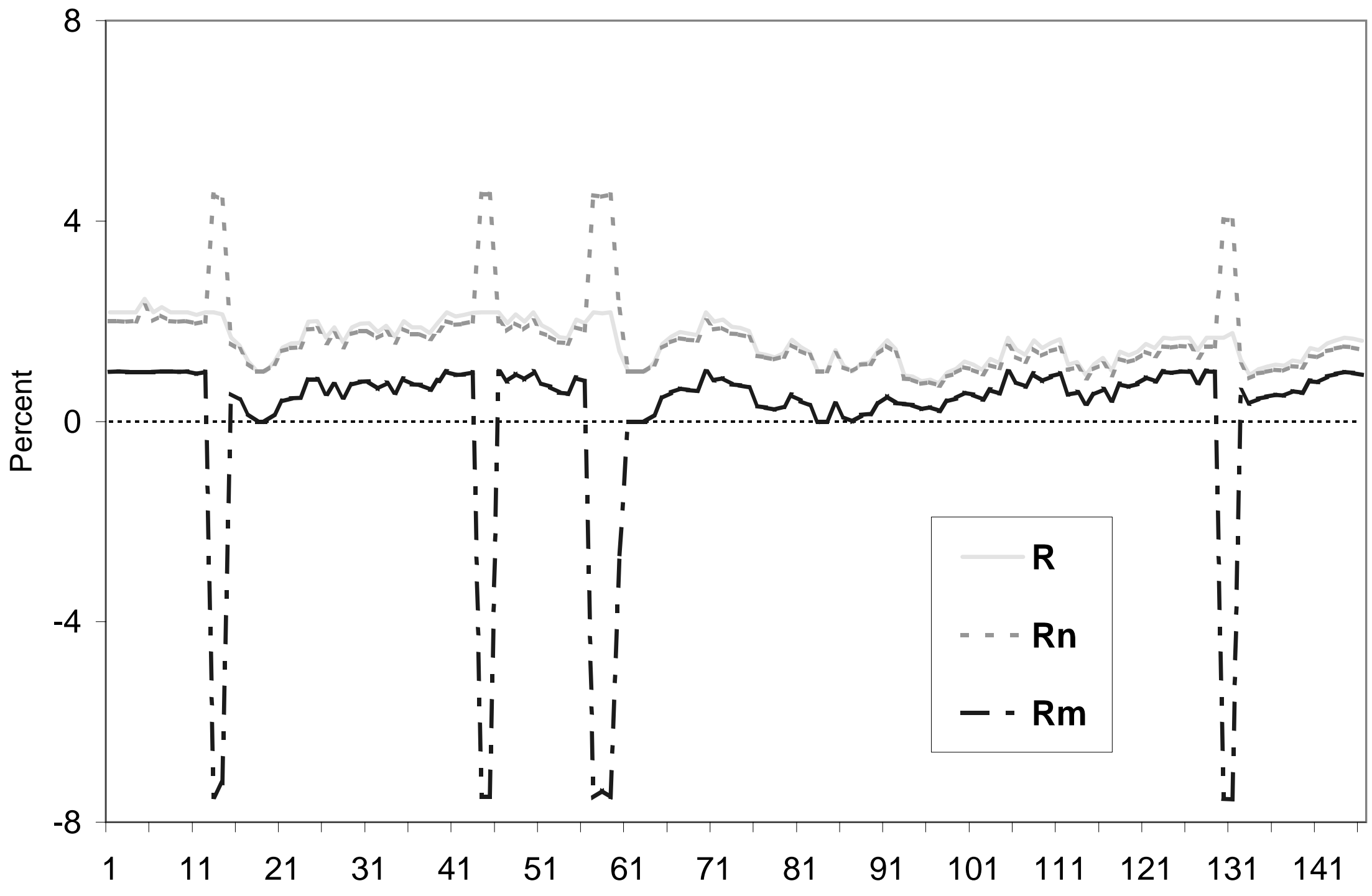


Figure 10 -- Call Loan Rates, Monthly 1890 - 1910

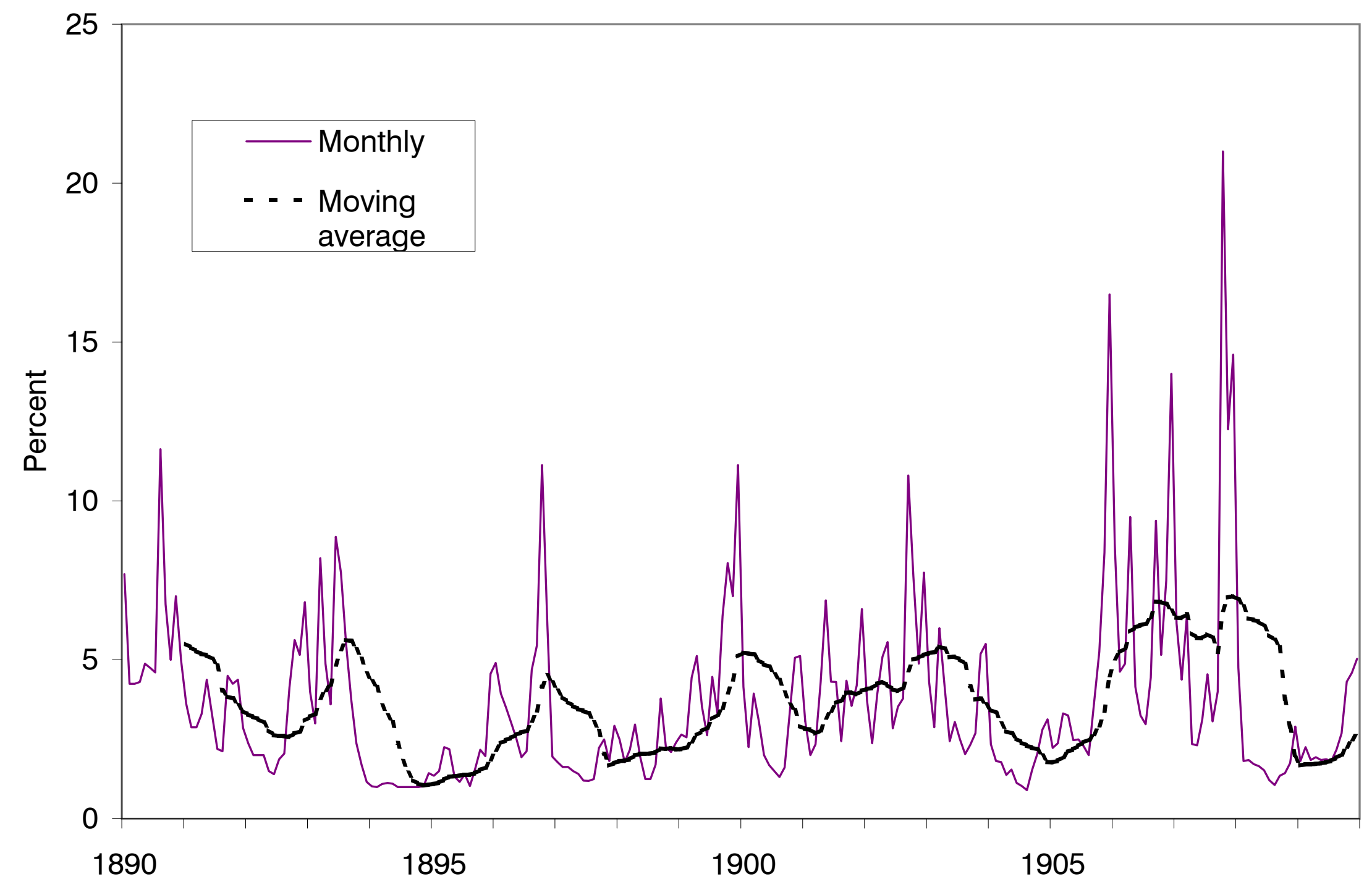

